\title{
Maitorotuisten sonnien laiduntaminen b) Vaikutus käyttäytymiseen
}

Leena Tuomisto ${ }^{1)}$, Paula Martiskainen ${ }^{2)}$, Arto Huuskonen ${ }^{1)}$, Leena Ahola ${ }^{2)}$, Jaakko Mononen ${ }^{2)}$ ja Risto Kauppinen $^{3)}$

${ }^{1)}$ Maa- ja elintarviketalouden tutkimuskeskus, Pohjois-Pohjanmaan tutkimusasema, Tutkimusasemantie 15, 92400 Ruukki.etunimi.sukunimi@mtt.fi

${ }^{2)}$ Kuopion yliopisto, Soveltavan biotekniikan instituutti, PL 1627, 70211 Kuopio. etunimi.sukunimi@uku.fi

${ }^{3)}$ Savonia-ammattikorkeakoulu, Maaseutuala, PL 72, 74101 Iisalmi.risto.kauppinen@savonia-amk.fi

\section{Tiivistelmä}

Tämän tutkimuksen tarkoituksena oli selvittää laiduntamisen vaikutusta maitorotuisten sonnien käyttäytymiseen. Kokeessa käytettiin yhteensä 19 maitorotuista ayrshire- ja holstein-friisiläissonnia. Laidunkauden alkaessa sonnit olivat noin 15 kuukauden ikäisiä. Kaksi ryhmää (4 ja 5 sonnia) siirrettiin kahdelle laidunlohkolle (0,1 ha/eläin). Kaksi viiden sonnin ryhmää jätettiin eristämättömään pihattoon kahteen osakuivikepohjaiseen ryhmäkarsinaan (6,4 m²/eläin). Laitumet kasvoivat yksivuotista kauraraiheinänurmea tai monivuotista timoteinurmea. Pihatossa sonneille annettiin vapaasti säilörehua. Kaikille eläimille annettiin lisäksi ohraa 5 kg/sonni/vrk ja kivennäistä 150 g/sonni/vrk. Sonnien käyttäytymistä tarkkailtiin yhden vuorokauden ajan heinäkuun alussa ja heinäkuun lopussa. Tarkkailujen aikana laidunsonnit olivat yksivuotisilla kaura-raiheinänurmea kasvavilla lohkoilla. Laitumella tarkkailut tehtiin suoralla seurannalla ja pihatossa videonauhoilta. Tarkkailumenetelmänä käytettiin hetkellistä seurantaa kuuden minuutin otantavälillä.

Laidunsonnit käyttivät syömiseen (laiduntaminen, rehun syöminen ruokintakaukalosta) enemmän aikaa kuin pihattosonnit. Rakenteiden nuolemiseen ja nakertamiseen käytetyssä ajassa ei ollut eroa koeryhmien välillä heinäkuun alussa, mutta heinäkuun lopussa rakenteiden manipuloimista havaittiin enemmän pihatossa. Stereotyyppistä kielenpyöritystä esiintyi hyvin harvoin, eivätkä koeryhmät eronneet sen määrässä. Heinäkuun alussa märehtimistä esiintyi enemmän pihatossa kuin laitumella, mutta heinäkuun lopussa koeryhmien välinen ero tasoittui. Sosiaalisen puskemis- ja nuolemiskäyttäytymisen määrässä ei ollut eroa koeryhmien välillä. Muuta sosiaalista käyttäytymistä (seurustelu, seksuaalinen käyttäytyminen) oli heinäkuun alussa enemmän laidunsonneilla kuin pihattosonneilla, mutta heinäkuun lopussa eroa ei enää ollut. Hankaamista esiintyi enemmän pihatossa kuin laitumella. Itsensä nuolemisessa ei ollut eroa koeryhmien välillä. Joutilaana tai tarkkaavaisena seisoskelussa ei ollut eroa koeryhmien välillä. Myöskään joutilaana makaamiseen tai nukkumiseen käytetyssä ajassa ei ollut eroa koeryhmien välillä.

Ero syömiseen käytetyssä ajassa johtuu ryhmien erilaisista ruokinnoista. Laidunsonnit keräsivät itse ravintonsa laitumelta kun taas pihattosonneille säilörehu tarjottiin valmiiksi silputtuna. Ahtaampi pihattoympäristö ei lisännyt pihattosonnien puskemiskäyttäytymistä. Laitumella sonnien saama liikunta parantanee eläinten lihaskuntoa ja voi siten edistää eläinten hyvinvointia. Laitumella sonnien mahdollisuuksista turkin hoitoon tulisi huolehtia tarjoamalla niille sopivia hankaamiskohteita. Tässä vertailussa molemmat kasvatusympäristöt osoittautuivat hyväksyttäviksi sonnien hyvinvoinnin kannalta, koska vakavista hyvinvointiongelmista kertovia käyttäytymismuutoksia ei havaittu kummassakaan ympäristössä. Täytyy ottaa kuitenkin huomioon, että tässä tutkimuksessa sonneilla oli myös pihatossa tilavammat olot kuin tavanomaisessa naudanlihantuotannossa.

Asiasanat: naudanlihantuotanto, tuotantoympäristö, sonnit, laiduntaminen, pihatto, käyttäytyminen, hyvinvointi 


\section{Johdanto}

Kuluttajat ja lainsäädäntö antavat yhä enemmän arvoa eettiselle, eläimen hyvinvoinnin huomioivalle eläintuotannolle (Sørensen ym. 2001). Mahdollisuutta lajityypilliseen käyttäytymiseen pidetään eräänä tärkeistä eläinten hyvinvointia määrittelevistä tekijöistä. Naudoilla tämä tarkoittaa varsinkin mahdollisuutta vapaaseen liikkumiseen, laiduntamiseen ja kanssakäymiseen lajitovereiden kanssa. Tavanomaisessa naudanlihantuotannossa maitorotuiset sonnit on kuitenkin perinteisesti kasvatettu sisätiloissa ympäri vuoden. Kesäaikainen laidunnus voisi parantaa lihanautojen hyvinvointia tarjoamalla eläimille mahdollisuuden lajinmukaisempaan käyttäytymiseen kuin perinteisemmissä kasvatusympäristöissä. Tämän tutkimuksen tarkoituksena oli selvittää laiduntamisen vaikutuksia kasvatuksen loppuvaiheessa olevien maitorotuisten sonnien käyttäytymiseen. Vertailueläiminä olivat kylmäpihatossa kasvatetut sonnit.

\section{Aineisto ja menetelmät}

\section{Eläimet, kasvatusympäristöt ja ruokinta}

Koe tehtiin Maa- ja elintarviketalouden tutkimuskeskuksen Pohjois-Pohjanmaan tutkimusasemalla Ruukissa kesällä 2004. Kokeessa käytettiin yhteensä 19 maitorotuista ayrshire- ja holsteinfriisiläissonnia. Koe alkoi 8.6. ja päättyi yhdentoista viikon kuluttua 23.8. Kokeen alkaessa sonnit olivat noin 15 kuukauden ikäisiä. Sonnit olivat vasikkana olleet laidunnuskokeessa (Martiskainen ym. 2004). Edeltävän talven sonnit olivat viettäneet eristämättömässä kylmäpihatossa ryhmäkarsinoissa. Kokeen alkaessa neljän ja viiden sonnin ryhmät siirrettiin kahdelle peltolaitumelle. Kaksi viiden sonnin ryhmää jätettiin kylmäpihattoon kahteen ryhmäkarsinaan. Laitumelle siirretyt sonnit olivat olleet laitumella edellisenä kesänä. Sekä laitumella että pihatossa sonnit kasvatettiin samoissa 4 - 5 eläimen ryhmissä, joissa ne olivat viettäneet talven.

Molemmilla laidunryhmillä oli käytössään viisi laidunlohkoa. Kolme lohkoista oli yksivuotisia kaura-raiheinälaitumia ja kaksi monivuotisia timoteilaitumia. Laidunlohkolla oli tilaa eläintä kohden noin 0,1 ha. Eläimet siirrettiin lohkolta toiselle keskimäärin viikon välein. Kylmäpihatossa sonnit olivat 4 x 8 m karsinoissa (6,4 m²/eläin). Karsina oli jaettu puoliksi takaosassa sijaitsevaan oljella ja turpeella kuivitettuun makuualueeseen ja etuosassa sijaitsevaan betonipohjaiseen lantakäytävään. Ruokintakaukalo sijaitsi karsinan etuosassa, ja ruokailutilaa eläintä kohden oli noin 0,7 m. Kaikille sonneille annettiin väkirehua (ohra) $5 \mathrm{~kg} / \mathrm{sonni} / \mathrm{vrk}$ ja kivennäistä $150 \mathrm{~g} / \mathrm{sonni} / \mathrm{vrk}$. Laitumella väkirehu tarjottiin ruokintakaukalosta, jossa oli ruokailutilaa eläintä kohden 0,5 - 0,6 m. Laitumella molemmilla sonniryhmillä oli omat, siirrettävät juomavesitankkinsa. Pihatossa eläimillä oli käytössään yksi juomavesitankki.

\section{Käyttäytymistarkkailut}

Sonnien käyttäytymistä tarkkailtiin heinäkuun alussa (heinä alku) ja heinäkuun lopussa (heinä loppu), molempina kertoina yhden vuorokauden (klo 00:00 - 24:00) ajan. Sonnien käyttäytymistä havainnoitiin laitumella suoralla seurannalla ja pihatossa videoimalla käyttäen aikaviivenauhureita. Laidunryhmien tarkkailut tehtiin poutapäivinä. Laiduneläimet olivat molempina tarkkailukertoina kauraraiheinälaitumilla. Laiduneläinten tarkkailuissa kaksi tarkkailijaa vuorotteli neljän tunnin jaksoissa. Samat tarkkailijat myös analysoivat pihaton videonauhat samalla periaatteella neljän tunnin jaksoissa.

Tarkkailumenetelmänä käytettiin hetkellistä seurantaa kuuden minuutin otantavälillä (Martin ja Bateson 1993). Hetkellisellä seurannalla havainnoitiin eläimen asento ja käyttäytymistoiminto. Muuttujien tilastollinen testaus tehtiin SPSS for Windows 11.5 -ohjelmalla. Koeryhmien välisessä vertailussa käytettiin riippumattomien ryhmien t-testiä normaalisti jakautuneilla muuttujilla ja Mann-Whitney testiä muuttujilla, jotka eivät olleet normaalisti jakautuneita. Tarkkailukertojen välisessä tarkastelussa käytössä olivat vastaavasti verrannollisten parien t-testi ja Wilcoxonin testi.

\section{Tulokset ja tulosten tarkastelu}

\section{Syömiskäyttäytyminen}

Laidunsonnit käyttivät laiduntamiseen/kuivikkeen maisteluun enemmän aikaa molempina tarkkailukertoina (heinä alku ja heinä loppu) kuin pihattosonnit (Taulukko 1). Pihattosonnit puolestaan kuluttivat enemmän aikaa ruokintakaukaloon jaetun rehun syömiseen kuin laidunsonnit. Yhteensä syömiseen 
(laiduntaminen, kuivikkeen maistelu, annetun rehun syöminen ruokintakaukalosta) kului aikaa enemmän laitumella kuin pihatossa. Ryhmien väliset syömiseen käytetyn ajan erot selittyvät laidun- ja pihattosonnien erilaisilla ruokinnoilla. Laitumella sonnit keräsivät itse ravintonsa laitumelta, kun taas pihatossa eläimille rehu tuotiin eteen valmiiksi silputtuna. Myös edellisenä kesänä sonnien ollessa vielä vasikoita syömiskäyttäytymiseen kulutetussa ajassa havaittiin samanlainen ero laidun- ja pihattoeläinten välillä (Martiskainen ym. 2004). Veden juomiseen käytetyssä ajassa ei havaittu eroa ryhmien välillä.

Usein toistuvaa ja pitkäkestoista rakenteiden nuolemista ja nakertamista sekä kielen stereotyyppistä pyörittämistä pidetään naudoilla epänormaaleina käyttäytymismuotoina (Wiepkema 1983). Esimerkiksi rajoitetun karkearehuruokinnan on todettu lisäävän näitä toimintoja (Graf 1993). Vaikka pihatossa eläimillä oli vähemmän syömiseen liittyvää tekemistä kielelleen kuin laitumella, rakenteiden nuolemista ja nakertamista havaittiin heinäkuun alussa yhtä paljon molemmissa kasvatusympäristöissä. Heinäkuun lopussa käyttäytymistä kuitenkin esiintyi enemmän pihatossa kuin laitumella. Stereotyyppistä kielenpyöritystä havaittiin hyvin harvoin, eikä ryhmien välillä ollut eroa sen määrässä.

Heinäkuun alussa märehtimistä esiintyi enemmän pihatossa kuin laitumella. Heinäkuun lopussa märehtiminen lisääntyi laitumella, eikä ympäristöjen välillä enää ollut eroa sen määrässä. Heinäkuun alussa yksivuotisten kauraa ja raiheinää kasvavien laitumien kasvusto oli vielä melko harvaa ja lyhyttä. Laidunsonnit saattoivat syödä kasvuston mukana myös jonkin verran multaa, ja sonneilla olikin havaittavissa lievää ripulia tarkkailujen aikana. Ruuansulatushäiriöt mahdollisesti selittävät laiduneläinten vähäisemmän märehtimisajan heinäkuun alussa.

\section{Sosiaalinen käyttäytyminen}

Laidun- ja pihattosonneilla havaittiin yhtä paljon sosiaalista nuolemista ja toisen eläimen puskemista (Taulukko 2). Myös aikaisemmassa tutkimuksessa hereford-rotuisilla sonneilla näitä käyttäytymistoimintoja esiintyi yhtä paljon vastaavissa olosuhteissa, metsätarhassa ja pihatossa (Tuomisto ym. 2004). Puskemiskäyttäytymisen osalta tulokset ovat ristiriidassa hiehoilla, härillä ja lehmillä tehtyjen tutkimusten kanssa, joissa agonistinen käyttäytyminen (uhkailu, puskeminen, alistuminen) lisääntyi eläintiheyden kasvaessa (Kondo ym. 1989, O’Connell ym. 1989). Syyksi agonistisen käyttäytymisen lisääntymiselle on esitetty ahtauden aiheuttamia vaikeuksia dominoivan eläimen väistämisessä (Wierenga 1983).

Tässä tutkimuksessa pihattokarsinan olosuhteet eivät liikkuma- ja ruokailutilan osalta vastanneet tavanomaisia olosuhteita naudanlihantuotannossa. Pihattokarsinoissa eläimillä oli tilaa 6,4 $\mathrm{m}^{2} /$ eläin, mikä on 2,4 m²/eläin enemmän kuin eläinsuojelusäädöksissä suositellaan minimitilaksi. Myös ruokailutilaa oli pihattokarsinoissa enemmän kuin eläinsuojelusäädösissä annetaan minimivaatimukseksi (0,7 m/eläin vs. 0,3 m/eläin, kun rehua on jatkuvasti tarjolla). Runsaamman liikkuma- ja ruokailutilan vuoksi sonneilla saattoi tässä tutkimuksessa esiintyä vähemmän aggressioita kuin mitä voitaisiin havaita tavanomaisemmissa, ahtaamissa oloissa kasvatetuilla lihanaudoilla.

Aggressiivinen puskeminen liittyy usein tilanteisiin, joissa resurssit ovat rajallisia. Esimerkiksi ruokailutilan rajoittaminen lisää ruokailutilanteessa puskemista (Winckler 2000). Aggressiivisen puskemisen lisäksi tässä tutkimuksessa sonneilla esiintyi puskemiskamppailuja, joihin osallistui kaksi tai useampia eläimiä. Kamppailut vaikuttivat enimmäkseen vaarattomilta, ja niissä havaittiin usein leikkitappeluun kuuluvia piirteitä (Reinhard ja Reinhard 1982). Leikkimieliset puskemiskamppailut olivat todennäköisesti sonnien mielestä palkitsevia, koska eläimet houkuttelivat toisiaan leikkiin ja vapaaehtoisesti hakeutuivat näihin tilanteisiin. Sonneilla oli erityisen otolliset olosuhteet puskemiskamppailuille laitumella, jossa oli pitävä pohja ja runsaasti tilaa.

Muuta sosiaalista käyttäytymistä (toisen eläimen tutkiskelua, seksuaalista käyttäytymistä, seurustelua) havaittiin heinäkuun alussa enemmän laitumella kuin pihatossa. Heinäkuun lopussa muu sosiaalinen käyttäytyminen väheni laitumella ja koeryhmien välinen ero tasoittui. Heinäkuun alussa laidunsonnit märehtivät vähemmän ja seisoskelivat (joutilaana tai tarkkaavaisena) enemmän kuin heinäkuun lopussa. Naudoilla sosiaalista käyttäytymistä esiintyy usein laidunnusjakson päätteeksi (Hinch ym. 1982), ennen kuin eläimet asettuvat makuulle (Reinhardt ym. 1986). Samaan aikaan esiintyy usein myös joutilaana seisoskelua (Arnold \& Dudzinski 1978). Suurempi joutilaana seisomisen määrä voikin olla yhteydessä heinäkuun alun suurempaan muun sosiaalisen käyttäytymisen määrään laidunsonneilla. 
Taulukko 1. Sonnien ajankäytön jakautuminen prosentteina (kaikista käyttäytymishavainnoista) syömiskäyttäytymiseen ja kielenpyöritykseen heinäkuun alussa ja heinäkuun lopussa (keskiarvo \pm keskihajonta) laitumella ja pihatossa. P1: tilastollinen merkitsevyys kasvatusympäristöjen välisessä vertailussa kuukausittain (laidun vs. pihatto), P2: tilastollinen merkitsevyys tarkkailukertojen välisessä vertailussa kasvatusympäristöittäin (heinä alku vs. heinä loppu). Tilastollinen merkitsevyys: ***(P<0,001), ${ }^{* *}(\mathrm{P}<0,01),{ }^{*}(\mathrm{P}<0,05)$ ja $\mathrm{o}(\mathrm{P}<0,10)$.

\begin{tabular}{|c|c|c|c|}
\hline & Laidun $(\mathrm{n}=9)$ & Pihatto $(n=10)$ & $P 1$ \\
\hline \multicolumn{4}{|l|}{ Laiduntaa/ maistelee kuiviketta (1) } \\
\hline heinä alku & $13,2 \pm 4,4$ & $0,14 \pm 0,17$ & $* * * a$ \\
\hline heinä loppu & $16,0 \pm 4,5$ & $0,19 \pm 0,29$ & $* * * a$ \\
\hline$P 2$ & $c$ & $c$ & \\
\hline \multicolumn{4}{|l|}{ Syö rehua ruokintakaukalosta (2) } \\
\hline heinä alku & $2,4 \pm 0,7$ & $11,3 \pm 2,0$ & $* * * a$ \\
\hline heinä loppu & $2,1 \pm 1,1$ & $11,7 \pm 2,7$ & $* * * a$ \\
\hline$P 2$ & $c$ & $c$ & \\
\hline \multicolumn{4}{|l|}{ Syömiskäyttäytyminen yhteensä (1 ja 2) } \\
\hline heinä alku & $15,6 \pm 4,1$ & $11,5 \pm 2,1$ & $*^{b}$ \\
\hline heinä loppu & $18,1 \pm 4,1$ & $11,9 \pm 2,6$ & $* * b$ \\
\hline$P 2$ & d & d & \\
\hline \multicolumn{4}{|l|}{ Nuolee/ nakertaa rakenteita } \\
\hline heinä alku & $0,44 \pm 0,40$ & $1,5 \pm 1,8$ & $a$ \\
\hline heinä loppu & $0,19 \pm 0,31$ & $1,9 \pm 1,3$ & $* * * a$ \\
\hline$P 2$ & $c$ & $c$ & \\
\hline \multicolumn{4}{|l|}{ Pyörittää kieltään } \\
\hline heinä alku & $0,0 \pm 0,0$ & $0,21 \pm 0,30$ & $a$ \\
\hline heinä loppu & $0,0 \pm 0,0$ & $0,08 \pm 0,18$ & $a$ \\
\hline$P 2$ & $c$ & $c$ & \\
\hline \multicolumn{4}{|l|}{ Juo vettä } \\
\hline heinä alku & $0,19 \pm 0,22$ & $0,46 \pm 0,54$ & $a$ \\
\hline heinä loppu & $0,38 \pm 0,26$ & $0,72 \pm 0,67$ & $a$ \\
\hline$P 2$ & $c$ & $c$ & \\
\hline \multicolumn{4}{|l|}{ Märehtii } \\
\hline heinä alku & $21,2 \pm 7,2$ & $34,0 \pm 3,5$ & $* * *^{b}$ \\
\hline heinä loppu & $30,7 \pm 5,2$ & $33,8 \pm 2,6$ & $o^{a}$ \\
\hline$P 2$ & $*^{c}$ & $c$ & \\
\hline
\end{tabular}

${ }^{\mathrm{a}}$ Mann-Whitney -testi, ${ }^{\mathrm{b}}$ riippumattomien ryhmien t-testi, ${ }^{\mathrm{c}}$ Wilcoxonin testi, ${ }^{\mathrm{d}}$ verrannollisten parien t-testi

\section{Turkin hoito, liikkuminen, tutkiskelu ja joutilaana olo}

Karvapeitteen hoitoa hankaamalla havaittiin enemmän pihatossa kuin laitumella (Taulukko 2). Pihatossa eläimet pystyivät hankaamaan itseään karsinan rakenteisiin milloin tahansa, mutta laitumella mahdollisia hankaamiskohteita olivat ainoastaan ruokintakaukalo ja vesitankki. Itsensä nuolemisessa ei ollut eroa ryhmien välillä.

Laitumella sonnit kävelivät enemmän kuin pihatossa, mikä on luonnollinen seuraus laitumen suuremmasta tilasta. Kävelemisessä ei ole huomioitu kävelemistä laiduntamisen aikana, mikä kasvattaa huomattavasti liikkumisen määrää laidunsonneilla. Liikunnalla on havaittu positiivisia vaikutuksia mm. nautojen sorkkaterveyteen ja liikuntaelimistön kuntoon (Greenough ym. 1981). Ympäristön tutkiskeluun käytetyssä ajassa ei havaittu eroa ryhmien välillä. Joutilaana/tarkkaavaisena seisoskelussa ei ollut eroa laidun- ja pihattosonnien välillä, mutta kesän edetessä laidunsonnien seisoskelu vähentyi. Tämä voi selittyä märehtimisen lisääntymisellä, jolloin eläimille jäi vähemmän aikaa joutilaana oloon. Joutilaana makaamista/nukkumista havaittiin yhtä paljon molemmissa kasvatusympäristöissä. 
Taulukko 2. Sonnien ajankäytön jakautuminen prosentteina (kaikista käyttäytymishavainnoista) eri toiminnoille (syömiskäyttäytymistä lukuun ottamatta, kts. Taulukko 1) heinäkuun alussa ja heinäkuun lopussa (keskiarvo \pm keskihajonta) laitumella ja pihatossa. P1: tilastollinen merkitsevyys kasvatusympäristöjen välisessä vertailussa kuukausittain (laidun vs. pihatto), P2: tilastollinen merkitsevyys tarkkailukertojen välisessä vertailussa kasvatusympäristöittäin (heinä alku vs. heinä loppu). Tilastollinen merkitsevyys: ***(P<0,001), **(P<0,01), $*(\mathrm{P}<0,05)$ ja $\mathrm{o}(\mathrm{P}<0,10)$.

\begin{tabular}{rccc}
\hline & Laidun $(\mathrm{n}=9)$ & Pihatto (n=10) & $P 1$ \\
\hline Nuolee toista eläintä/ on toisen eläimen nuoltavana & & \\
heinä alku & $2,6 \pm 1,5$ & $2,4 \pm 1,0$ \\
heinä loppu & $1,2 \pm 1,3$ & $1,3 \pm 0,9$ \\
$P 2$ & $o^{c}$ & $o^{c}$
\end{tabular}

Puskee toista eläintä/ on toisen eläimen puskettavana

$$
\begin{array}{r}
\text { heinä alku } \\
\text { heinä loppu } \\
\text { P2 }
\end{array}
$$$$
\begin{gathered}
4,0 \pm 2,0 \\
3,7 \pm 1,5 \\
d
\end{gathered}
$$$$
4,1 \pm 1,6
$$$$
3,6 \pm 2,4
$$

Muu sosiaalinen käyttäytyminen (toisen eläimen tutkiskelu, seksuaalinen käyttäytyminen, seurustelu)

$$
\begin{array}{r}
\text { heinä alku } \\
\text { heinä loppu }
\end{array}
$$

$$
\begin{gathered}
4,0 \pm 1,7 \\
2,3 \pm 1,2 \\
* *^{d}
\end{gathered}
$$$$
2,1 \pm 1,1
$$$$
2,4 \pm 1,2
$$

Hankaa itseään

$$
\begin{array}{r}
\text { heinä alku } \\
\text { heinä loppu }
\end{array}
$$$$
0,56 \pm 0,52
$$$$
1,4 \pm 0,7
$$

$$
\text { P2 }
$$

$$
0,68 \pm 0,63
$$$$
1,5 \pm 0,9
$$

$$
d
$$

Nuolee itseään

$$
\begin{array}{r}
\text { heinä alku } \\
\text { heinä loppu } \\
P 2
\end{array}
$$$$
1,2 \pm 1,2
$$$$
0,69 \pm 0,65
$$$$
0,82 \pm 0,61
$$$$
\text { a }
$$

$$
2,1 \pm 2,0
$$

Kävelee (ei laidunna)

$$
\begin{array}{r}
\text { heinä alku } \\
\text { heinä loppu }
\end{array}
$$$$
\begin{gathered}
2,5 \pm 0,7 \\
2,8 \pm 0,6 \\
d
\end{gathered}
$$$$
1,4 \pm 0,6
$$$$
1,4 \pm 0,7
$$

b




\section{Johtopäätökset}

Ero syömiseen käytetyssä ajassa johtuu ryhmien erilaisista ruokinnoista. Laidunsonnit keräsivät itse ravintonsa laitumelta, kun taas pihattosonneille rehu tarjottiin valmiiksi silputtuna. Laiduneläinten vähäisempi märehtimisaika heinäkuun alussa voi johtua nuoren yksivuotisen kasvuston ja mullan syömisen aiheuttamista lievistä ruuansulatushäiriöistä. Ahtaampi pihattoympäristö ei lisännyt aggressioita pihattosonneilla verrattuna tilavammissa oloissa olleisiin laiduneläimiin. Sonnien saama liikunta laitumella parantanee eläinten liikuntaelimistön kuntoa ja voi siten edistää eläinten hyvinvointia. Sonnien mahdollisuuksista turkin hoitoon tulisi huolehtia tarjoamalla niille sopivia hankaamiskohteita laitumella. Tässä vertailussa molemmat kasvatusympäristöt osoittautuivat sonnien hyvinvoinnin kannalta hyväksyttäviksi, koska vakavista hyvinvointiongelmista kertovia käyttäytymismuutoksia ei havaittu kummassakaan ympäristössä. Täytyy ottaa kuitenkin huomioon, että tässä tutkimuksessa sonneilla oli myös pihatossa tilavammat olot kuin tavanomaisessa naudanlihantuotannossa.

\section{Kirjallisuus}

Arnold, G.W. \& Dudzinski, M.L. 1978. Ethology of free-ranging domestic animals. Elsevier Scientific Publishing Company. Amsterdam. $198 \mathrm{~s}$.

Graf, B. 1993. Abnormal oral behaviours in fattening bulls: incidence, causation and implications. Teoksessa: Nichelmann, M., Wierenga, H.K. \& Braun, S. (toim.). Proceedings of the international congress on applied ethology, Berlin 1993. Darmstadt, Germany: KTBL. s. 47-52.

Greenough, P.R., MacCallum, F.J., Weaver, A.D. 1981. Lameness in cattle. Toinen painos.

Kondo, S., Sekine, J., Okubo, M. \& Asahida, Y. 1989. The effect of group size and space allowance on the agonistic and spacing behavior of cattle. Appl. Anim. Behav. Sci. 24: 127-135.

Martin, P. \& Bateson, P. 1993. Measuring behaviour. An introductory guide. Toinen painos. Cambridge, UK: Cambridge university press. $222 \mathrm{~s}$.

Martiskainen, P., Huuskonen, A., Mononen, J., Kauppinen, R., Tuomisto, L., Kiljala, J., Lindeberg, H., Ahola, L. \& Rekilä, T. 2004. Laidunnuksen vaikutukset maitorotuisten sonnivasikoiden käyttäytymiseen ja hyvinvointiin luomunaudanlihantuotannossa. Teoksessa: Hopponen, A. \& Rinne, M. (toim.), Maataloustieteen Päivät 2004. Suomen maataloustieteellisen seuran tiedote 19. 4 s.

O’Connell, J., Giller, P. S. \& Meaney, W. 1989. A comparison of dairy cattle behavioural patterns at pasture and during confinement. Irish J. Agric. Res. 28: 65-72.

Reinhard, V. \& Reinhard, A. 1982. Mock fighting in cattle. Behav. 81: 1-13.

Reinhardt, V., Mutiso, F.M. \& Reinhardt, A. 1978. Social behaviour and social relationships between female and male prepubertal bovine calves (Bos indicus). Appl. Anim. Ethol. 4: 43-54.

Sørensen, J.T., Sandøe, P. \& Halberg, N. 2001. Animal welfare as one among several values to be considered at farm level: the idea of an ethical account for livestock farming. Acta Agric. Scand., Sect. A, Animal Sci., Suppl. 30: 11-16.

Tuomisto, L., Huuskonen, A., Martiskainen, P., Mononen J. \& Kauppinen, R. 2004. Behaviour of beef bulls in a pen and in a forest paddock in summer. Teoksessa: Hänninen, L. \& Valros, A. (toim.), Proceedings of the 38th international congress of the ISAE. s. 197.

Wiepkema, P. R., Broom, D. M., Duncan, I. J. H. \& van Putten, G. 1983. Abnormal behaviours in farm animals. A report of the Commission of the European Communities. $16 \mathrm{~s}$.

Winckler, C. 2000. Effects of feeding and manger space allowance on feeding behaviour and agonistic interactions in dairy cattle. Teoksessa: Ramos, A., Pinheiro Machado Filho, L.C. \& Hötzel, M.J. (toim.), Proceedings of the $34^{\text {th }}$ International Congress of the ISAE, Florianapólis, Brazil. s. 214. 